\title{
Molecular-Virusological Antiproteinasno Therapy Grippa (Review of Literature and Own Research)
}

\section{Valentina Divocha*}

Luhansk State Medical University of Ukraine, Rubezhnoe, Ukraine

*Corresponding Author: Divocha VA, Luhansk State Medical University, Rubezhnoe, Ukraine.

DOI: $10.31080 /$ ASMI.2020.03.0533
Received: December 23, 2019

Published: February 26, 2020

(C) All rights are reserved by Valentina

Divocha.

\section{Abstract}

New ways of approaching the problem of obtaining antiviral drugs based on fundamental research into the mechanisms of virus reproduction and their interaction with the host's body, using its proteolytic system, have been outlined. There are two ways to protect the virus-stricken cell in two ways: blocking the breakdown of hemagglutinin of the influenza virus by specific antibodies in the intercellular space and blocking the thripsin-like protein sprocage inhibitor hemagglutinin precursor protein in the cell itself.

Keywords: Serine Proteinase; Inhibitors; Flu

\section{Introduction}

The development of effective measures to combat viral infections remains one of the most pressing health problems. The successes of fundamental research have allowed us to penetrate deeply into the mechanisms of viral reproduction, structural organization and function of individual viral structures, but have not yet provided reliable and effective ways to combat the vast majority of pathogens of mass acute viral diseases of humans and animals [1-5]. The solution to this problem requires the attraction of new ideas and approaches, in the search for a new research methodology in the field of fundamental and practical virology, in a comprehensive analysis of the interaction of two systems - the parasite and the host a comprehensive analysis of the interaction of the two systems - the parasite and the host. This interaction is a single whole, representing a set of internal relationships of two opposite beginnings. The end result of this interaction is genetically determined by the host and the pathogen and depends on the level of regulation, both the process of viral reproduction and the body's defenses. The balance between these processes determines the outcome of the interaction, which can lead to the death of the host, his complete recovery or the formation of a chronic form ofinfection [6-9].

The biology of viral pathogens is associated with difficulties in the creation of selective antiviral drugs. Advances in biochemistry and molecular biology in recent years, revealing the specifics of virus reproduction, provide new approaches for directed intervention in the viral reproduction cycle.

\section{Proteolytic activity associated with influenza virus}

For the first time in the early 1980s, when cleaning and concentrating the influenza virus, different strains, to obtain polyvalent influenza vaccines, we were faced with the fact that we cannot free the influenza virus from proteolytic activity [10]. To address this issue, we have improved cleaning methods). To address this issue, we have improved cleaning methods. But no matter what cleaning method they use, we were not able to free the influenza virus from proteolytic activity. This connection cannot be broken neither the impact of $0.1 \%$ of sodium dodecissulfate solution, nor the forces of electrophoretic mobility of charged negatively molecules, nor centrifugal forces. On the basis of this, we can talk about a power- 
ful hydrophophobe interaction of viral and cellular molecules [1113]. Determining proteolytic activity in purified and concentrated influenza virus drugs can serve as a marker of the quality of the virus's purification [14].

Proteolytic activity by other authors has been detected in the Sendai virus [15], foot-and-mouth disease [16-17], and hepatitis B [18].

To study the nature of the virus-associated proteinase, we obtained specific immune rat serums to normal choorionanise shells of a chicken embryo and neutralized the proteinazu associated with the influenza virus and concluded that proteinase, primarily associated with the influenza virus, is of cellular origin $[10,14]$.

As early as the early 1960s, the presence of antigenic components in viral drugs, the origin of which is the host cell, was confirmed by a number of researchers [19-21]. Thus, in the composition of purified particles of influenza virus, parainfluenza virus Sendai and Newcastle disease virus found heterogene antigen type Forsman, antigen similar to the group-like antigen A of humans, and antigen, carrying the species specificity of those cells on which the virus develops [22].

Currently, "neoalbumine" antigen (OA) is the only host antigen rationed and controlled in the manufacture of influenza vaccines [23]. An analysis of the purified preparations of the influenza virus for the presence of proteolytic activity in our studies showed that purification of the influenza virus by ultracentrifugation methods does not exempt the influenza virus from proteolytic activity. In the sucrose gradient (15-60\%), proteolithic activity is clearly divided into several isoforms [11].

The pre-cleaning of the polyacrylamide gel in electrophoresis also led to a clear separation of thripsin-like proteinaze into 7 - 9 fractions of high proteolytic activity. A similar enzyme profile has been found in the normal chorionallanise fluid and chorionallanis shells of the chicken embryo. The difference was that proteolytic activity was much lower and proteinase was generated faster from elyats. Antiserums to the chorinallanous membranes neutralized the proteolytic activity associated with the influenza virus [24-25].

The results led us to conclude that the influenza virus is associated with the serininus protein-containing trypsin-like type of cellular origin, which has molecular heterogeneity. This protein is firmly absorbed as on the surface, so on deep-located virion polypeptides, as evidenced by our studies with the removal of its superficial glycoproteins hemagglutinin and neuraminidase, with the help of twin-90 and ester. The bulk of proteolytic activity was concentrated in the RNP fraction. The presence of cellular elements in the composition of the purified influenza virus was ascertained by many authors [26-29], but no one had previously studied the presence of proteolytic enzymes in the composition of the purified influenza virus. In RNP preparations, we found proteinase activity. As our studies have shown, the purified influenza virus has always contained a protein with proteolytic activity. While the release of $\mathrm{V}$, an antigen that represents a complex of hemagglutinin and neuraminidase, no protein activity was detected. In RNP preparations, we found proteinase activity.

This suggests that this enzyme plays an important role in the morphogenesis of the influenza virus and largely determines its pathogenic and virulent properties.

The dynamics of trypsin-like protein alike activity in the process

\section{influenza virus}

The system of proteins and inhibitors is represented in the body by a large group of proteins. Proteolytic enzyme inhibitors act as a constant level of appropriate enzymes in the body, are found with the latter in constant dynamic equilibrium. Disruption between enzymes and inhibitors is important for the development of pathological processes [30].

Our research shows that in the lungs and serum of uninfected animals and chicken embryos, the levels of protein activity and infungal protein adhesive activity are in balance, which is disrupted by infection with the virus Influenza A.

In the infectious process, there are several periods that are characterized by varying degrees of virus reproduction, protein activity levels and inhibiting activity proteinavirus.

The most profound changes occur in the first hours after infection. Thus, 6 hours after infection, the amount of proteinaza in the lungs and serum of infected animals is reduced and inhibiting activity increases [24]. A similar phenomenon has been observed for The Newcastle Disease and Aueska Disease [31].

Thus, it can be assumed that in the first minutes after infection, observed changes in the enzyme-inhibitor balance in the animal 
appear to be related to the fact that the flu viruses used contain both enzymes and their inhibitors. Further, the decrease in proteolytic activity is associated with the corresponding accumulation of proteinase inhibitor in the infected body. Influenza-infected cells appear to induce the appearance of an inhibitor, both in the lung tissue and in the serum. Consequently, lung inhibitors are as if the first line of defense of the organ when acting different strains of the influenza virus.

Of great interest is the nature of proteinase accumulating in infected lungs. Our preliminary studies have shown that proteinases are heterogeneous and only one of them is able to correctly break down hemagglutinin and cause an increase in infectious activity.

In our research, we found protein inhibitors of different natures.

Other authors also claim that seren protein inhibitors are induced by influenza viruses. Thus, the allantoic fluid inhibitor differed [32] from the trypsin inhibitors of the 17-day amniotic fluid [33] and the ovomucoide in the chicken embryo protein. The allantoise fluid protein inhibitor had properties similar to the properties of subtilisin inhibitors, described for ovoinhibitors and ovomacroglobulin of chicken embryos, black bean seeds [34] and Streptomyces Subtilisin inhibitor [35].

Proteinase inhibitors in the reproduction cycle of adenoviruses [36], the vesicular stomatitis virus [37] and the simple type 2 herpes virus [38] are virus-specific inhibitors that block critical metabolic stages of infected cells. Our research suggests that virusinduced inhibitors detected in the first hours after infection, block the activity of host cell proteinase, leaving influenza virus proteins protected from proteolytic hydrolysis, when the inhibitors run out, the proteinaza begins to break down hemagglutinin and the virus titre increases, so, 6 hours after infection, an additional inhibitor should be introduced to block protein activity [39].

In studying changes in protein and inhibitory activity in chicken embryos, large and small infecting doses of influenza virus $A / R$ $\mathrm{R} / 8 / 34$ found that they experienced similar changes as in the body of white mice. During the period of maximum accumulation of infectious and hemagglutinating activity ( 24 hours), neither proteinase nor inhibitory activity was detected [40]. S. Ewasyshin and G. R. Sabina [41] has been shown to replicate different strains of influenza viruses when the release of different strains of influenza viruses shows a distinct suppression of the protein-resistant activity of the allantoisic fluid when the release of the infectious virus approaches its maximum.

The complete suppression of inhibiting activity was delayed by a day and occurred by 48 hours. During the inhibitor blockade (48 - 96 hours), protein activity increased rapidly. This suggests that there are different inhibitors. The first peak of the inhibitor acts as the body's protective function for the introduction of infection. The second peak of the inhibitor was suppressed slightly, although during this period the infectious virus reached its maximum, with a small dose of infection the second peak was not changed at all. The third peak was sharply depressed by a large dose and changed little with the action of a small dose. If the primary function of the third inhibitor is to preserve the infectious virus by protecting it from proteolytic degradation, the interference with the synthesis of the inhibitor may be of important therapeutic importance [42].

Excretion and cleaning of thripsi-like proteinase from the lungs mice

From the lungs of healthy mice was isolated, 6 isoforms of trypsin-like proteinase, and 8 isoforms from the lungs of infected mice, in which specific proteolytic activity increased dramatically compared to the source material [43]. Danenberg A. M. and E. L Smith isolated from the lungs of cattle two isoforms of alkaline proteinase, in their substrate specificity resembling chimotripsine [44].

By studying the physical and chemical properties of thripsinlike protein, isolated from uninfected and infected lungs, the optimum $\mathrm{pH}$ for proteiniase itoforms from uninfected lungs varied in the $\mathrm{pH}$ zone of $7-8$, closer to $\mathrm{pH} 8$, while for proteinase isolated from the infected lungs, optimum $\mathrm{pH}$ was deflected into the acidic side, especially for THE VI isoform and was in the $\mathrm{pH}$ zone 4 - 5 [45]. merge their shell with the cell membrane and increase the conductivity of the cell membrane, at low pH values $(5,0-5,5)$.

Analyzing the molecular mass of isolated isioforms of trypsinlike proteinases derived from the lungs of healthy mice found that they were all not homogeneous and contained several proteins.

In our research, we had to address the question of how to sterilize the isolated isoforms so as not to lose proteolytic activity? 0,22 MM MDSC cells were the breeding of the virus. The highest hemagglutin titre was obtained in the action of the VI isoform, while the infectious titer was the highest in interaction with the III isoform. 
Enzymes isolated from the lungs of infected mice did not contain an isoform that would increase the infectious titger above the control numbers. It seems that the isoform responsible for the development of infection does not necessarily have the highest rates of hemagglutinin.

The effect of antiproteinase immune sera on the propagation of influenza virus

In the literature, there is a consensus that that the infectious process is only possible when hemagglutinin is divided into two subunits NA1 and NA2, and that this is due to cellular proteinase [46]. But total cellular proteinase has heterogeneity and consists of six isoforms with different molecular, substrate specificity, different sensitivity to inhibitors and different effects on hemagglutinin formation titers and infectious activity during the multiplication of influenza virus in MDS cells.

For the first time in 1987, studies have been conducted on cellular antiprotein immunoglobulins that block the development of influenza infection. For the isolation of several fractions of trypsin proteinase isoforms from uninfected lungs of mice, a large number of animals was required, which indicates that in a healthy body proteinases are calculated in a minimal amount, but play a huge role in virus penetration. Cellular proteinases are apparently involved in the "stripping" of influenza virions. It is known that antiviral drugs such as remantadine, interferon and bonaftan are known to prevent the virus shell from merging with endothelial membranes and precede the transcription stage of the viral genome [3]. Proteolytic enzyme inhibitors suppress the reproduction of the influenza virus at later stages. However, from the body's point of view, it would be more beneficial to prevent infection at an earlier stage- the stage of viral particles entering the cell.

According to the literature shown for influenza Viruses A, B and $C$ types, paramyxoviruses, rotaviruses, that viral particles acquired infection only after thripsin or trypsin-like proteinases, while chemotrypsin proteinase, inducing the slicing of surface proteins, their function and infection of embryos were not activated [47]. In our studies, antiproteinase immune sera (especially 4 groups) blocked trypsin activity, and the influenza virus did not multiply in the transplanted MDSC cell culture.

In the literature, we have not met data on the receipt of specific immune serums to trypsin-like proteinase, and, especially, do not mention its isoforms.
We have obtained hyperimmune rat serums to all thripsin-like proteins.

In studying the effects of antiprotein immune and normal serums on the reproduction of the influenza virus $\mathrm{A} / \mathrm{Phil} / 2 / 82$, in the presence of trypsin, on the cell culture of MDSC it was found that the immune serums of four groups in breeding 1:8 dose 0.2 $\mathrm{ml}$ per test tube [2] blocked the activity of trypsin and viral infection did not develop. Similarly, normal rat serum was affected at the same dose, which indicates a non-specific effect on their trypsin activity. However, the immune antiprotein serum of the fourth group suppressed the reproduction of the virus on the cells of MDSC (and in breeding 1:80 $\mathrm{ml}$ ), while the action of normal serum stopped in breeding 1:10 ml.

In studying the protective properties of antiproteinous serums and normal rat serum in white mice, infected in the intranasally, lethal dose of influenza virus A/PR/8/34 (IV passage), it was found that $100 \%$ of the death of control mice occurred on 4 - 5 days. Animals that were instilled with normal rat serum six times died on the $7^{\text {th }}$ day. In the treatment of mice with pools of immune sera I, II, IV, $\mathrm{V}$ and the VI animal mortality rate declined and occurred significantly later than in the control group, $30 \%$ of the animals did not die, but recovered [48].

The fourth serum pool was most effective, with $60 \%$ of the infected mice surviving, and on the $14^{\text {th }}$ day after infection in the serum and lungs, we did not detect either hemagglutin or infectious virus. The immune serum to the VI isoform did not protect mice from death at all, although the III isoform from VI differed only in one protein, with a molecular weight of $32 \mathrm{kDa}$ [49]. The presence of a protein with a mass of $32 \mathrm{kDa}$, which showed protamininsplitting activity in the flu virus indicates V.P. Lozitsky., et al [50]. We also, working in parallel with V. P. Lozitzky, found a high peak of protaminsplital activity, characteristic of allantois uninfected chicken embryos, which gave us the opportunity to assert that proteinase has a cellular origin [10].

Reducing the mortality of mice under the influence of antiprotein immune serum can apparently be associated with the ability to suppress the reproduction of the virus. This is particularly evident in the example of the fourth serum pool, which is simultaneously most active in the culture of MDSC tissue. 
We received immune antiproteinases serums and to nine isoforms isolated from the lungs of mice infected with the flu virus. Studying their protective effect, came to the conclusion that specific immune serums, to isoforms isolated from the lungs of infected mice did not have protective functions, on the contrary, the introduction of specific serums to I, II, IV, VIII and X isoforms intensified the reproduction of the influenza virus and the animals quickly died.

Thus, research on the protective properties of antiproteinous serums in influenza infection was conducted for the first time. Received positive results that open the possibility of creating drugs with a universal effect, which is very significant with the large variability of influenza viruses.

The second way to block a viral infection is to use trypsin-like protein inhibitors.

Therefore, the goal of further our research is to obtain a trypsin-like protein inhibitor from the lungs of healthy mice and infected with influenza A virus.

Gettingan inhibitor of trypsin-like proteins and studying their protective properties in deadly influenza in an experiment

Trypsin-like proteinasa plays a key role in the development of the pathological process in the body. It breaks down the outer protein of the influenza virus (hemagglutinin) into two subunits - NA1 and NA2 [51]. Only after splitting the virus penetrates the cell and begins to multiply [52]. A new approach to the treatment of influenza: blocking the proteolytic activation of the virus by proteinase inhibitors is currently considered the most promising [53]. The mechanism of the antiviral effect of inhibitors is associated with suppression of proteolytic activity [54]. Data from a series of virus models indicate that the mechanism of proteolytic activation has a general biological universal value. In picornaviruses and togas viruses, proteolytic activation with the formation of mature viral proteins. In influenza viruses and paramyxoviruses, proteolytic activation is associated with the breakdown of glycoproteins, which cause the virus to enter the cell. Inhibitors block the process of cutting viral proteins by inhibiting the activity of cellular enzymes. In the presence of cellular proteinase inhibitors, after one cycle of reproduction of the original virus with chopped proteins, viral offspring with undigested, functionally inactive viral proteins are formed. Virions are not capable initiate an infectious process in connection with the block of the early stages of the reproduction cycle - the absorption and penetration of the virus into the cell [55].

For the first time in world practice, we have isolated a trypsinlike protein inhibitor from the lungs of healthy mice. It was characterized by a high degree of purity and contained a small amount of impurities. The inhibitor had a molecular mass of 47500 Yes. Developed and patented method of obtaining and cleaning the inhibitor trypsin-like proteinases [56]. The dedicated inhibitor is similar tothe alpha-1-inhibitor of human serum proteinase (m.m. 48000 - 55000 Yes) and an egg protein trypsin inhibitor (m.m. 49000 Yes), but not similar to the trypsin inhibitor isolated from the lungs of cattle (a Kunitz-Northrop-type inhibitor) that had a molecular mass of 65,000 Da. Proteolytic activity of the isophyform trypsinlike protein test method, it was found that it suppressed the activity of almost all isoforms, except the fourth (41.8\%) eighth $(28.3 \%)$.

In our research, using a cellular inhibitor to suppress the development of influenza virus in chicken embryos, it has been found to inhibit the development of infectious and hemagglutinating activity and the formation of a common protein. At the same time, the trypsin-like protein inhibitor, isolated from the lungs of mice pre-infected with the influenza virus, did not have this ability. In further studies, we used an inhibitor to treat influenza infection in animals, which was isolated from the lungs of healthy mice. In the treatment of white mice pre-infected with a lethal dose of influenza virus, $80 \%$ of the animals recovered and remained alive for up to 14 days after infection.

The presence of trypsin-like protein inhibitors in industrial waste of gamma-globulin production

To obtain an antiviral drug that would have the least energy for humans, we used donated blood waste to produce gamma globulin and albumin.

According to our research, fresh canned human donor blood contained a large amount of trypsin-like protein inhibitor. Moreover, more inhibitor is contained in serum than in red blood mass. A year after storage at $-180 \mathrm{C}$, inhibitory activity persisted, but the activity was much lower than in fresh blood (from $450 \mathrm{~g} / \mathrm{l}$ to 70 $\mathrm{g} / \mathrm{l})$. In donated human blood, the amount of trypsin-like proteinase inhibitor was independent of the amount of proteinase. At the same time, in the blood of white mice there was a correspondence between proteinases and their inhibitors [56]. The mismatch be- 
tween proteinase and inhibitor in human blood, apparently, is due to the fact that the person suffered some kind of infectious disease or suffers from chronic infections. The serine proteinsof human blood are the X factor and with a molecular weight - 59 $\mathrm{kDA}$, plasmin, with a molecular weight - $85 \mathrm{kDA}$, and blood clotin with a molecular weight $-36 \mathrm{kD}$. Protein inhibitors in human blood are: antithrombin -3, alfa 2 - macroglobulin, alfa1 - globulin, alfa 2 - globulin and alfa1 - antitripsin. According to Yesiko Nagai1990 $\Gamma($.) the $\mathrm{X}$ factor breaks down the hemagglutinin of the influenza virus, In the only arginine site, on two subunits NA1 and NA2. Virus-activating protein as and Factor $\mathrm{X}$ is not only structurally but also functionally similar to each other. Bochringer Mannheim Biochemica refers to serinprotein proteins. At the first stage of obtaining gamma globulin and albumin from the $2+3$ fraction, according to Cohn, fibrinogen is ejected. Factor $\mathrm{X}$ is included in this waste. Centrifugate, which contains $481.11 \mathrm{mg}$ of trypsin-like proteinase inhibitor per kilogram of weight, is used for disposal. - In this centrifuge is a1 - antitrypsin. Antitrypsin - and1 or1 - inhibitor proteinasis is the main inhibitor of seren proteinases of human blood plasma [58].

In the second stage of obtaining gamma globulin for disposal is sediment containing prothrombin, alpha and beta-globulins and lipoids. This precipitation, according to our results, contains 469.87 mg of trypsin-like protein inhibitor per kilogram of weight. This precipitation includes antithrombin - 3 (AT-3) or heparin factor the regulator of the clotting system of blood. According to the OA. Markova., et al. (1989) in normal AT-3 content for donors ranged from 160 to 250 micrograms $/ \mathrm{ml}$. The zone of alpha-globulins also includes1-antitrypsin and2-macroglobulin [59-60].

In the third stage of receipt of gamma globulin, the waste is sediment containing profibrinolysine (plasminogen).

In the fourth stage of the deposition of gamma-globulin for disposal is centrifuge No.3. According to our data, the material of centrifugate № 3 contains 166.37 mg of trypsin-like protein.

Thus, the raw materials for obtaining a trypsin-like protein inhibitor can be waste after the first and second stage of the process, where the sediment is laundered by $2 / 3$ and prothrombin release. These wastes contain the largest amount of trypsin-like protein inhibitor.

\section{Conclusion}

Thus, one of the most important stages of development of many viruses in the host body is their introduction into the cell after predeproteinization. Regulating this stage of the virus development is one of the fundamental principles of their reproduction. Induction or introduction of a proteolytic virus activation inhibitor is one of the promising ways to treat viral diseases, including influenza.

\section{Bibliography}

1. Gendon YS. "Vaccines and chemotherapy drugs for the prevention of influenz". Virology 52.1 (2007): 4-10.

2. Slepushkin AN. "WHO World Programme for Epidemiological Surveillance and Influenza Control". Voprosy Virusologii 1 (2003): 46-48.

3. Kolobukhina LV. "Influenza Treatment and Prevention". RMJ 12.17 (2004): 16-17.

4. Burtseva EI. "Specific prevention of influenza in the current epidemic process: autoref. dis. for the ph.d. of". Medical Sciences (2005): 53.

5. OI Kiselyov., et al. "Results of the clinical study of the reactogenicity, safety and immunogenicity of Grifor vaccines on the elderly contingent (60 years and older)". Epidemiology 4.41 (2008): 36-39.

6. EN Burtseva., et al. "Sensitivity to remantadine and arbidol influenza viruses, which caused epidemic rises in the incidence in Russia in the 2004-season". Voprosy Virusologii 52.2 (2007):24-29.

7. ES Shevchenko., et al. "Specific anti-influenza chemotherapy drugs, justification for their use for prevention and treatment in Russia". Topical issues of infectious pathology and vaccine prevention in children (2007): 13-14.

8. PG Derebin., et al. "Antiviral activity of drugs Ferrovir and Derinap in relation to infection caused by the pathogenic variant of influenza A virus (H5N1) 1 (2006): 62-65.

9. Savinova OV., et al. "Individual and joint use of new derivatives of betuline and remantadine to inhibit reproduction of influenza virus". Modern problems of human infectious pathology: Sat. Scientific. Works 1 (2008): 137-141.

10. Divocha VA., et al. "Cell Proteas of the influenza virus". Theses reports of the 2 nd Congress of Infectious Diseases of the USSR K (1983): 36-38. 
11. Divocha VA. "Studying of proteolytic activity in the process of purification of influenza virus by centrifugation". Odessa Medical Journal 1 (2003):16-19.

12. Divocha VA. "Cell components associated with influenza virus”. Odessa Medical Journal 2.46 (1998): 8-10.

13. Divocha VA., et al. "Proteolytic lung enzymes associated with influenza virus" Materials of the 12th Congress of microbiologists, epidemiologists and parasitologists (1996): 147-148.

14. Divocha VA. "Cell trypsin-like proteaza is a marker of the quality of the purification of the influenza virus". Actual Medical Biotechnology Issues (1991): 30-31.

15. Zhirnov OP and AG Bukrinskaya. "Study of the proteins of the Sendai virus: proteolytic activity in viral particles". Virology Issues 5 (1977): 571-577.

16. Dool TR and Colen T. "Observations and implications of proteolysis in preparation of foot and mouth disease virus". Developmental Biology Stand 50 (1981): 261-266.

17. Grubman Marvin J. "Fur there characterization of a proteinkinase from foot-and-morith disease virus". Journal of Virology 44.3 (1982): 1102-1105.

18. Wolfram H Qerlich., et al. "Specificity and localization of the hepatitis B virus associated protein kinase". Journal of Virology 42.3 (1982): 761-766.

19. Rovnova ZI and PN Kosiakov. "The chlorina s.I. study of the properties of host antigens in the structure of microviruses". Virology Issues 4 (1966): 413-417.

20. Chepulis GKS and VM Yudanov. "Biological role of host antigens in mixoviruses". Virology Issues 2 (1968): 151-162.

21. EA Friedman and GM Bohnevich. "Antigens host in the structure of influenza viruses". Killed Influenza Vaccine (1976): 163-173.

22. AL Platonova., et al. "Identification and identification of the host cell antigen as part of influenza virus B". Virology Issues 3 (1987): 159-163.

23. MN Matrosovich., et al. "Immunoenzyme analysis of "nonalbumin" substrate impurities in inactivated influenza vaccines". Virology Issues 4 (1989): 491-495.

24. Divocha VA. "Cell components associated with influenza virus”. Odessa Medical Journal 2.46 (1998): 8-10.
25. Divocha VA. "Influenza virus and enzymes cells". Experimental and Clinical Medicine (1999): 100-105.

26. Polyanskaya NJ and AB Jebrun. "Allantois neoalbumincomponents of whole-virion influenza vaccines". Chromatography in Biology and Medicine: Science (1983): 249-250.

27. Zhdanov VM., et al. "Family Orthomyxoviridae". Private Virology 2 (1982): 139-185.

28. Webster RQ and WQ Laver. "Antigenic variations of influenza viruses The influenza viruses and influenza (E. D. Kilbourn)". Academia Research (1975): 209-314.

29. AB Zhebrun., et al. "Host antigens in purified preparations of the influenza virus". Etiology and Specific Prophylaxis of Influenza (1982): 70-81.

30. Zorin NA. "The role of macroglobulin proteins in the mechanisms of infection". Yu MEI 3 (2004): 105-112.

31. Kurchenko GA. "Proteinase of chicken embryo cells and their role in the reproduction of viruses: autoref. Dis. to study. Kanda degree". Biological Sciences (1974): 21.

32. Bainter $\mathrm{K}$ and $\mathrm{G}$ Feher. "Fate of egg white tripsin inhibitor and start of proteolysis in developing chick embryo and nervy hatched chick". Development Biology 36 (1973): 272-278.

33. H Lineweaver and CW Murray. "Identification of the trypsin inhibitor of egg white ovomucoid". Journal of Biological Chemistry 171 (1947): 565-581.

34. Sciedl DS. et al. "Practical characterization of a subtilisin inhibitor from black bean sceds". International Journal of Peptide and Protein Research 19 (1982): 153-157.

35. T Ikenaka., et al. "Amino acid sequence of an alkaline protease inhibitor (Streptomyces subtilisin inhibitor) from Streptomyces". Journal of Biochemistry 76 (1974): 1191-1209.

36. Levine A and Ginsberg. "Mechanisms by which fiber antigen inhibits multiplication of type 5 adenovirus" Journal of Virology 1 (1967): 747-757.

37. B Baxt and R Bablanian. "Mechanisms of VSV-induced cytopathic effects". Virology 72 (1976): 72 382-392.

38. Hill T., et al. "Herpes simplex virus type 1 and 2 induce shutoff of host protein synthesis by different mechanisms in Friend erythroleukemie cells". Journal of Virology 45 (1983): 241250. 
39. Divocha VA., et al. "Change of protease activity in the lungs of mice infected with influenza virus A". Issues of Virology 5(1999): 370-377.

40. Divocha VA. "Changes in chicken embryo under the action of strain Virus". Odessa Medical Journal 2 (2000): 100-105.

41. Ewasyshyn ME and LR Sabina. "The activity of the protease of allantoic fluid in the process of infection with the influenza virus". Acta Virology 30 (1986): 109-118.

42. DivochaV A., et al. "Dynamics of changes of proteolytic activity of enzymes in the process of development of influenza virus B". Bulletin of Scientific Researches 4 (2006): 51-53.

43. Divocha VA., et al. "The separation and purification of trypsin proteases from the lungs of white mice". Medical Chemistry 3.3 (2001): 73-77.

44. AM Dannenberg and EL Smith. "Proteolytic enzymes of lang". Journal of Biological Chemistry 215.1 (1955): 45-53.

45. Divocha VA., et al. "Study of physical-chemical properties of isenzymes of Trypsin proteases". Medical Chemistry 3.4 (2001): 31-34.

46. GG Skehel., et al. "Changes in the conformation of influenza virus hemagglutinin at the ph optimum of virus-mediated membrane fusion". Proceedings of the National Academy of Sciences79.4 (1982): 968-972.

47. R Rott., et al. "Influenza viruses, cell enzymes and pathogenicity" American Journal of Respiratory and Critical Care Medicine 152 (1995): 516-519.

48. Divocha VA., et al. "Defensive role of anti-proteous immune serums in experimental influenza". Mechnikov and development of modern natural science". Conf (1995): 102-103.

49. Divocha VA. "Protective action of antiproteic whey". Odessa Medical Journal 371 (2002): 14-17.

50. VP Lozitsky., et al. "The participation of the proteolysis system in the implementation of the virulence of the influenza virus and the development of the infectious process: the antiviral effect of protease inhibitors". Questions of Virology 4 (1987): 413-419.

51. W Weis., et al. "Structure of the influenza virus hemagglutinin complexed with its receptor, silica acid". Nature 333.6172 (1988): 426-431.
52. Scholtissek C. "Influenza A viruses with noucleaved hemagglutinin are not internalised after adsorbtion". Archives of Virology 90.12 (1986): 159-163.

53. Maleev Yu Z. "The role of neuraminidase inhibitors in the prevention and treatment of influenza". Kidney Pharmacology and Therapeutics (2007): 1-6.

54. LV Kolobukhina., et al. "The effectiveness of oseltamivir (Tamiflu)in influenza in adults during the epidemic rise of morbidity in Russia in the season 2006 -2007 r.g". Invo virology 4 (2008): 23-27.

55. Veremeenko KN., et al. "Proteolysis in normal and in pathology”. Health (1988): 200.

56. Divocha VA. "NBP Method of receiving a tripsinoid protease inhibitor". Applicant and Patentoholder Divocha (2019).

57. Divocha VA., et al. "Change of protease activity in the lungs and serum of mice infected with influenza b virus". Issues of Virusology 3 (1992): 176.

58. Bin Goton., et al. "An endoprotease homologons to the blood clotting factor $\mathrm{X}$ as a determinant of viral tropism in chick embryo". JORNAL EMBO 9.12 (1990): 4189-4195.

59. SM Podyarene., et al. "Immunoafin cleaning a1 - protease inhibitor from human blood plasma”. Virology Issues 5 (1989): 96-99.

60. Markov OA. et al. "Immunoenzyme method of antithrombin detection 3". Medical Chemistry 5 (1989): 127-130.

\section{Assets from publication with us}

- Prompt Acknowledgement after receiving the article

- Thorough Double blinded peer review

- Rapid Publication

- Issue of Publication Certificate

- High visibility of your Published work

Website: https://www.actascientific.com/

Submit Article: https://www.actascientific.com/submission.php

Email us: editor@actascientific.com

Contact us: +919182824667 